\title{
Few-quantum-dot lasing in photonic crystal nanocavities
}

\author{
Liu, Jin; Ates, Serkan; Stobbe, Søren; Lorke, Michael; Lodahl, Peter
}

Published in:

ACP Technical Digest

Publication date:

2012

Document Version

Publisher's PDF, also known as Version of record

Link back to DTU Orbit

Citation (APA):

Liu, J., Ates, S., Stobbe, S., Lorke, M., \& Lodahl, P. (2012). Few-quantum-dot lasing in photonic crystal nanocavities. In ACP Technical Digest (pp. AF4A.3). Optical Society of America.

\section{General rights}

Copyright and moral rights for the publications made accessible in the public portal are retained by the authors and/or other copyright owners and it is a condition of accessing publications that users recognise and abide by the legal requirements associated with these rights.

- Users may download and print one copy of any publication from the public portal for the purpose of private study or research.

- You may not further distribute the material or use it for any profit-making activity or commercial gain

- You may freely distribute the URL identifying the publication in the public portal

If you believe that this document breaches copyright please contact us providing details, and we will remove access to the work immediately and investigate your claim 


\title{
Few-quantum-dot lasing in photonic crystal nanocavities
}

\author{
J. Liu, S. Ates, S. Stobbe, M. Lorke and P. Lodahl \\ DTU Fotonik, Department of Photonics Engineering, Technical University of Denmark, \\ Ørsteds Plads 343, DK-2800 Kgs. Lyngby, Denmark \\ jinl@fotonik.dtu.dk
}

A very smooth lasing transition in photonic crystal nanocavities with embedded quantum dots is observed and compared to the theory. Decay rate measurements reveal that only a few quantum dots are feeding the cavity.

OCIS codes: (140.3410) Laser resonators; (140.3460) lasers; (270.3430) Laser theory

Photonic crystal nanolasers have attracted great interest both for fundamental research and applications in the past decade. In photonic crystal cavities, the leakage to optical modes is strongly reduced, which increases the spontaneous emission coupling factor, $\beta$. This is a crucial parameter for the threshold characteristics of lasers. With increasing $\beta$, the well-known step-like threshold behavior becomes smoother. Although the smooth lasing transitions of photonic crystal nanolasers were observed and fitted by traditional rate equation models [1], a systematic comparison between experiments and more advanced semiconductor models of photonic crystal nanolasers is still missing [2]. The goal of this work is to get a deep understanding of the quantum dots based nanocavity lasers by comparing experiments to theory.
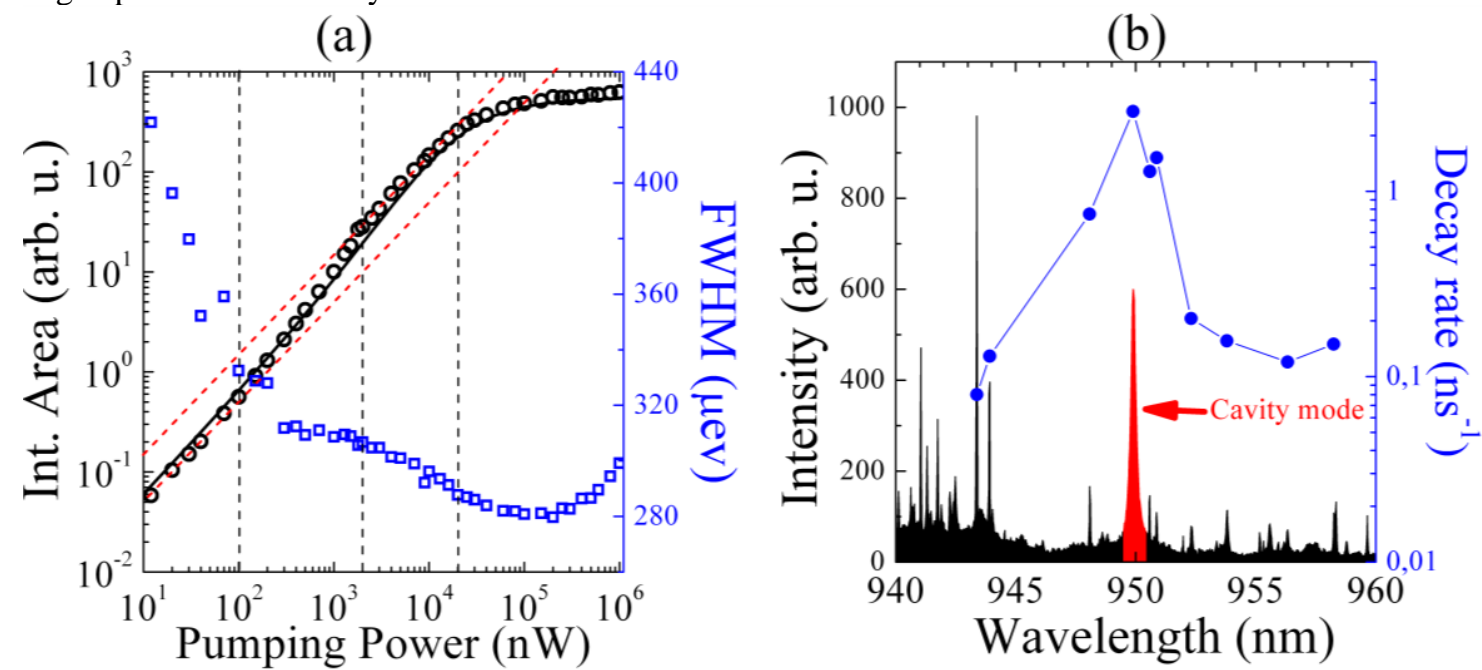

Fig. 1 (a) The output power (black circles) and the linewidth (blue squares) of the cavity mode as a function of excitation power. The solid line shows the theoretical curve as explained in the text. Red lines are guides to the eye for a linear increase of output power with a slope of one. (b) The emission spectra (black) of quantum dot-cavity system for $100 \mathrm{nW}$ pumping power and decay rates (blue circles) for different wavelength. The cavity mode is highlighted in red.

Excitation power dependent cavity mode intensity and linewidth are shown inFig. 1(a). In regimes I and III, the output intensity increases linearly with the input power. A smooth nonlinear increase of output power can be clearly traced in regime II, which is the signature of onset of lasing. The theory predicts a similar behaviour as observed experimentally by assuming realistic parameters of cavity quality factor $\mathrm{Q}=7800$, the number of quantum dots $\mathrm{N}=$ 4 , spontaneous emission coupling factor $\beta=0.15$ and the mode volume $\mathrm{V}=0.52 \mu \mathrm{m}^{3}$. The linewidth decreases in regime I , is stable in regime II, and slowly decreases in regime III [3]. Saturation is observed in regime IV.

The emission spectra with low pumping power and the decay rates of quantum dots are shown in Fig. 1 (b). Below saturation, many exciton peaks in the spectra can be indentified as well as the fundamental cavity mode around 950 $\mathrm{nm}$. Only three quantum dots have comparable decay rates to that of the emission at the wavelength of the cavity mode and most of the decay rates from quantum dots are strongly inhibited by the photonic band gap. This indicates that only a few quantum dots are feeding the cavity mode in the lasing transition process. 

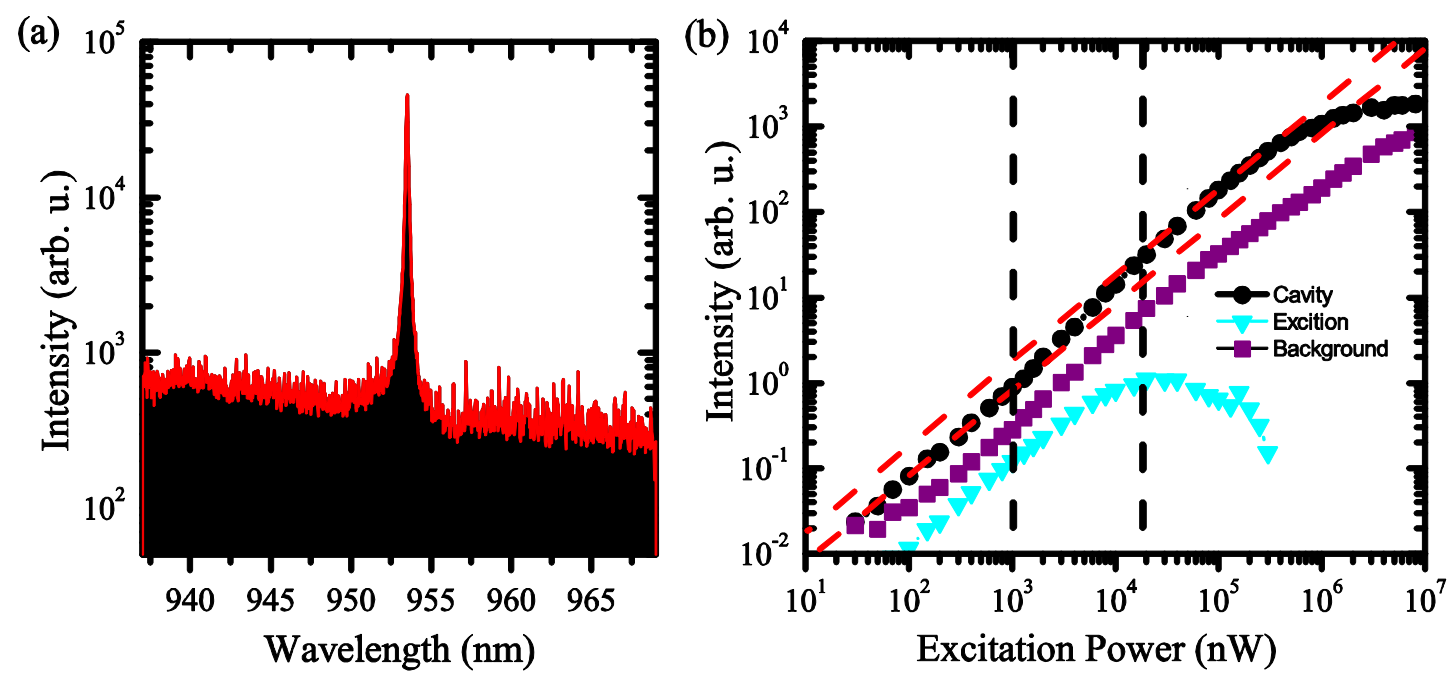

Fig. 2 (a) High excitation power spectrum in logarithmic scale where the background emission can be clearly seen. (b) Power series of the cavity mode,exciton line and the background emission.

In order to understand the physical mechanism of quantum dots lasers, a high excitation power spectrum is plotted in a logarithmic scale in Fig. 2(a). Apart from the cavity mode, a constant background emission has been observed. The broad background emission is attributed to the multi-exciton states under high excitation powers. In Fig. 2(b), the emission intensities of an exciton state, background emission and the cavity mode have been plotted as a function of the excitation power. The exciton emission increases linearly with the excitation power before the saturation while the background emission increases linearly all the way with excitation power. Only the cavity mode shows a nonlinear increase of the intensity with the excitation power, showing that lasing has been achieved. Since the exciton emission saturates around the laser threshold power, it is very unlikely that the lasing is supported by the exciton state of quantum dots. On the contrary, the very broadband background emission which can be easily resonant with the cavity mode is keeping on increasing above the lasing threshold power and feeds the laser mode.

In conclusion, we have experimentally realized Few-quantum-dot lasing in photonic crystal nanocavities. Due to mesoscopic nature of the qantum dots, the broadband multi-exciton states can be easily resonant with the cavity mode and contribute to the lasing. This feature enables a self-tuning mechanism for the gain media, which is very attractive for the device applications.

[1]S. Strauf, K. Hennessy, M.T. Rakher, Y.-S. Choi, A. Badolato, L.C. Andreani, E.L. Hu, P.M. Petroff, and D. Bouwmeester, "Self-Tuned Quantum Dot Gain in Photonic Crystal Lasers," Phys. Rev. Lett. 96, 127404 (2006).

[2] C. Gies, J. Wiersig, M. Lorke, and F. Jahnke, "Semiconductor model for quantum-dot-based microcavity lasers," Phys. Rev. A 75, 013803 (2007).

[3] G. Björk, A. Karlsson, and Y. Yamamoto, "On the linewidth of microcavity lasers," Appl. Phys.Lett. 60, 304 (1992). 